\title{
Study of Coal Mine Ventilation System Optimization based on Ventsim
}

\author{
Jing Gang ZHANG ${ }^{1,2}$, Cheng Yu SUO ${ }^{1}$ \\ ${ }^{1}$ College of Safety Engineering, North China Institute of Science \& Technology, Beijing 101601,China ${ }^{2}$ School of Resource \\ and Safety Engineering, China University of Mining and Technology( Beijing) ， Beijing 100083，China
}

\begin{abstract}
This article is based on the situation of too large coal mine ventilation resistance in the Majiagou coal mine. According to Majiagou coal mine late production plans, it measures resistance comprehensively, analyses the resistance distributions and the problems exist in the ventilation systems and comes up with targeted optimization programs. By studying the ventilation system model, as well as adjusting the system parameters, Ventsim software is applied to study ventilation system in Majiagou coal mine. Design of mine ventilation is proved practical in the mine ventilation system optimizations, thus Ventsim software can not only be used in the ventilation network calculation and merry-demand simulation and dynamic of wind flow, but also can be used to assist in the short-term and long-term planning for ventilation system, it is of a certain significance of guidance to find the problems in the mine management and optimizations of the ventilation network.
\end{abstract}

Keywords: Ventsim; three-dimensional ventilation; ventilation calculation; optimizations

\section{Ventsim three-dimensional ventilation simulation system}

Ventsim is based on independent platform mine ventilation implement software, the system has very good compatibility, 3-d model is generated by putting basis data from other mine design software or the ventilation software into the system conveniently. The real 3-D artwork technology is adopted by building a model, complicated mine ventilation process will be shown directly with $3-\mathrm{D}$ by the consumers. By coloring different data in different colors, ventilation process key data and weak link are clear at a glance. By building 3-d ventilation system model, network ventilation is resolved and wind machine is selected preferably, thereby, ventilation effect is detected and controlled to satisfy the shaft design and management requests.

\section{Situation of the coal mine}

Single wing diagonal drawer-type is adopted in the mine ventilation. New wind of shaft enters $2 \mathrm{nd}, 3 \mathrm{rd}$, 4 th to 5 th horizontal shaft bottom car parks, then to the 11th dark shaft, eighth horizontal bottom, 13th dark shaft and10th horizontal transportation roadway one by one. Part of wind flow from 0005 the into the wind after washing face to 0005 return air duct by 9905 return air up to 8905 blind shaft, the 7905 blind shaft to 5 level crosscutting back in 5605 up to 3 level alleys finally to 2505 a return air lane in the west wind well back into the ground. The present type 62 A13-N024 is a main ventilating machine, whose power is 1000 $\mathrm{kW}$, angle of the ventilating machine blade installation is 45 degree .

\section{3-d model building and ventilation system evaluation analysis}

\subsection{Resistance measurement and basic data acquisition}

Base point measuring method of precise barometer are adopted to measure main mine ventilation line, more than 150 points. Both measurement methods and instruments meet the requirements, besides, the data obtained by measuring are reliable and error precision is not 
beyond the demand.

\subsection{Building the 3-d}

According to the actual situation of the mine design, with the help of AutoCAD graphic software, ventilation systematic diagram is drawn as the latest one, then every roadway centerline is traced, and AutoCAD graph is saved in the form of DXF. Then the entity roadway is generated when DXF file is imported into Ventsim system. Node level data are used to model the node fu elevation. Initial three-dimensional model is completed.

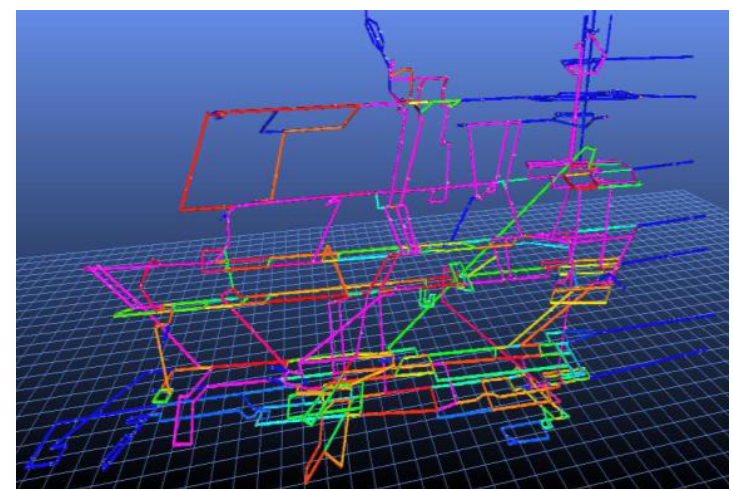

Figure 1 3-D stereo model of Majiagou coal mine

\subsection{Input the main data and conduct ventilation status simulation}

Basic data and material are measured based on the mine ventilation resistance. The tunnel section shape, area, the type of support and parameter of wind resistance are assigned to the corresponding roadway. The present situation of Majiagou mine ventilation system is simulated to be resolved and the condition of the underground is simulated actually. By regulating wind resistance of some branches, the wind speed, air volume and temperature of 3-d stereo model are basically consistent with practical tunnels. The results are shown in the table 1 .

Table 1 The main tunnel calculating results of current situation simulation

\begin{tabular}{c|c|c|c|c|c}
\hline Branch & Phrase & $\begin{array}{c}\text { Tunnel } \\
\text { name }\end{array}$ & Resistance (pa) & $\begin{array}{c}\text { Air volume } \\
\left(\mathbf{m}^{\mathbf{3} / \mathbf{s})}\right.\end{array}$ & $\begin{array}{l}\text { wind resistance } \\
\left(\mathbf{K g} / \mathbf{m}^{7}\right)\end{array}$ \\
\hline 1 & $1-2$ & Third well & 74.781 & 69.69 & 0.0154 \\
\hline 5 & $2-3$ & $\begin{array}{c}5 \text { horizontal } \\
\text { shaft bottom }\end{array}$ & 91.88 & 39.92 & 0.0577 \\
\hline 8 & $3-98$ & 11th of mine 1 & 51.849 & 39.2 & 0.0337 \\
\hline 9 & $4-98$ & 11th of mine 2 & 94.113 & 90.84 & 0.0114 \\
\hline 12 & $4-102$ & 13th of mine 1 & 65.345 & 72.33 & 0.0125 \\
\hline 13 & $102-5$ & 13th of mine 2 & 15.216 & 38.54 & 0.0102 \\
\hline 41 & $23-24$ & Westerly Wells & 65.351 & 155.5 & 0.0027 \\
\hline 42 & $24-105$ & $\begin{array}{c}\text { Well westerly } \\
\text { wind tunnel }\end{array}$ & 142.971 & 160.44 & 0.0059 \\
\hline
\end{tabular}

\subsection{Mine ventilation system evaluation analysis}

The division of three sections is based on: from the inlet air head into the wind alleys for inlet air section; From the inlet air cross to return for cross wind section; From the return air cross to exhaust wellhead for return air section.

Table 2 Resistance distribution of Ventilation system

\begin{tabular}{|c|c|c|c|c|}
\hline System Name & Section & Segment & $\begin{array}{c}\text { ventilating } \\
\text { resistance }(\mathbf{P a})\end{array}$ & $\begin{array}{c}\text { The percentage of } \\
\text { the total } \\
\text { resistance of } \\
\text { system }(\%)\end{array}$ \\
\hline \multirow{3}{*}{$\begin{array}{l}0423 \text { one surface } \\
\text { ventilation system }\end{array}$} & Air inlet section & 1 9 & 634.627 & 22.68 \\
\hline & & $9-13$ & 177.261 & 6.33 \\
\hline & Air retuning & $13-105$ & 1986.412 & 70.99 \\
\hline
\end{tabular}




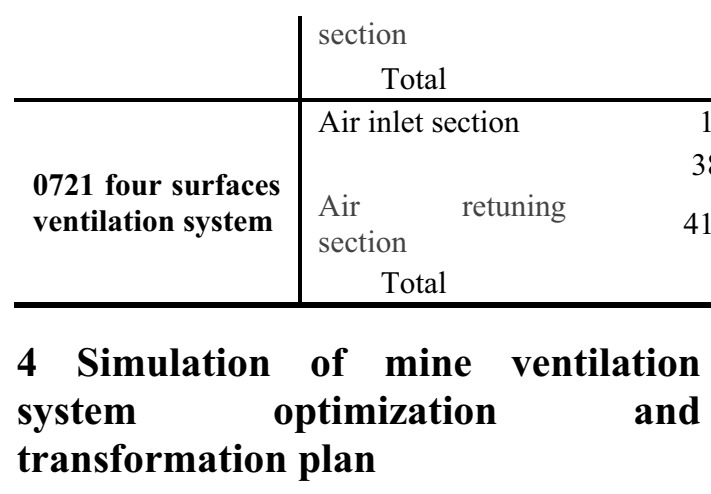

\section{1 Putting forward the optimization schemes}

After multiple communications and discussions with the field engineering and technical personnel, we put forward the two optimization scheme and simulate them as follow:

1) Scheme 1: Renovation project for all of the tunnels: a comprehensive renovation was

\begin{tabular}{ccc} 
& 2798.3 & 100 \\
\hline $1-38$ & 738.179 & 26.42 \\
$38-41$ & 406.012 & 14.53 \\
$41-105$ & 1649.78 & 59.05 \\
& 2793.971 & 100
\end{tabular}

conducted to wind eyes and 13 tunnels whose wind resistance is larger than others, ventilation ability is improved by expanding lane engineering and regulating system. (Wind resistance after repairing the tunnels can be got according to the similar tunnel experience values. They are shown in the Table 3)

2) Scheme 2: Based on the scheme 1, scheme 2 adopts high power fan: after implementations of expanding lane project, a great power counter-rotating fan of the west wind well BDK - 8 - No. 26 is simulated.

Table 3 the tunnels needing cleaning

\begin{tabular}{c|c|c|c|c}
\hline \multirow{2}{*}{ Branch } & Tunnel name & $\begin{array}{c}\text { Initial wind resistance } \\
\mathbf{( k g / \mathbf { m } ^ { 7 } )}\end{array}$ & $\begin{array}{c}\text { Wind resistance after } \\
\text { cleaning } \\
\left(\mathbf{k g} / \mathbf{m}^{\mathbf{7}}\right)\end{array}$ & $\begin{array}{c}\text { Tunnel } \\
\text { length(m) }\end{array}$ \\
\hline $19-21$ & $3205 \mathrm{C}$ & 0.0449 & 0.023 & 186 \\
\hline $54-19$ & 3 west13Shimen & 4.6949 & 2.4049 & 3000 \\
\hline $53-54$ & 5405 & 1.2293 & 0.3738 & 416 \\
\hline $53-55$ & 7905 & 30.4183 & 0.3738 & 416 \\
\hline $104-53$ & \multirow{2}{*}{8905} & 1.0909 & 0.5588 & 276 \\
\cline { 1 - 4 } & & 3.3426 & 1.7122 & 276 \\
\hline
\end{tabular}

\subsection{Simulation of data}

In 3-D model directly modify tunnel attribute value of resistance dismissing then simulate.
4.3 Simulation effect analysis and determination of the optimization scheme

In terms of technology, We can analyze as follows after comprehensively comparing the simulation results of every scheme.

Table 3 Comparison of simulation results

\begin{tabular}{|c|c|c|c|c|c|c|c|c|}
\hline \multirow[b]{2}{*}{ Parameters } & \multicolumn{4}{|c|}{ Westerly Wells } & \multicolumn{4}{|c|}{ Central system on the 2nd Air Shaft } \\
\hline & $\begin{array}{l}\text { Fans } \\
\text { negative } \\
\qquad(\mathrm{Pa})\end{array}$ & $\begin{array}{l}\begin{array}{l}\text { Fan } \\
\text { flow }\end{array} \\
\left(\mathrm{m}^{3} / \mathrm{s}\right)\end{array}$ & $\begin{array}{l}\text { change } \\
\text { value of } \\
\text { air } \\
\text { volume } \\
\quad\left(\mathrm{m}^{3} / \mathrm{s}\right) \\
\end{array}$ & $\begin{array}{l}\text { change } \\
\text { value of } \\
\text { Pressure } \\
\text { changes } \\
\quad(\mathrm{Pa})\end{array}$ & $\begin{array}{l}\text { Fans } \\
\text { negative } \\
\qquad(\mathrm{Pa})\end{array}$ & $\begin{array}{l}\text { Fan } \\
\text { flow } \\
\left(\mathrm{m}^{3} / \mathrm{s}\right)\end{array}$ & $\begin{array}{l}\text { change } \\
\text { value of } \\
\text { air } \\
\text { volume } \\
\quad\left(\mathrm{m}^{3} / \mathrm{s}\right)\end{array}$ & $\begin{array}{l}\text { change } \\
\text { value of } \\
\text { Pressure } \\
\text { changes } \\
\quad(\mathrm{Pa})\end{array}$ \\
\hline Status & 2815.34 & 155.5 & & & & & & \\
\hline One & 2637.18 & 166.44 & 10.94 & -214.154 & & & & \\
\hline Two & 3252.38 & 185.34 & 29.84 & 437.041 & & & & \\
\hline Three & 2972.96 & 151.88 & -3.62 & 157.621 & 2667.66 & 96.73 & & \\
\hline
\end{tabular}

The scheme one: west fan air pressure value decreases to $2637.186 \mathrm{~Pa}$, air volume increases to $166.44 \mathrm{~m}^{3} / \mathrm{s}$. Both have no obvious effects to the ventilation system, thus not achieving the desired results. It can be adopted as a basically scheme.
The scheme two: after simulating west ventilating shaft air volume increases to 185.34 $\mathrm{m}^{3} /$ which is close to the anticipated goal; Though the air pressure increases to $3252.381 \mathrm{~Pa}$, it is still difficult to accept this result.

The scheme three: Air volume of west 
ventilating shaft is calculated $151.88 \mathrm{~m} 3 / \mathrm{s}$, air pressure is $2972.961 \mathrm{~Pa}$, air volume of ventilating shaft 2 is $96.73 \mathrm{~m} 3 / \mathrm{s}$, air pressure is 2667.660 Pa. The air down hole wind points meet the requirements, in order to achieve the desired effect; this can be used as the best solution.

To sum up, the scheme three of Majiagou coal mine ventilation system optimization is the best choice.

\section{Comparisons with two-dimension ventilation calculating software in the practical application}

According to the measurement of the system parameters, we also use $2 \mathrm{~d}$ ventilation calculating software to simulate. We can get a result of similarities and differences by comparing and analyzing:

Simulations from Ventsim and two-dimension software are basically the same. Precision and accuracy have been up to the standard.

With the advance of the work, roadway changes and entire mine ventilation network diagram need repainting, and then every branch is reassign and finally calculation to simulate the current state. Workload is very big, and very easy to make a mistake. Use Ventsim $3 \mathrm{~d}$ ventilation simulation system, has been established because of $3 \mathrm{~d}$ model and actual mine is a one-to-one relationship, solution is directly in the $3 \mathrm{~d}$ models, do not need painting ventilation network diagram. Roadway change, directly on the $3 \mathrm{~d}$ model modification roadway. In additions and deletions or modify roadway attribute, the model will be automatic inspection to change, thus automatic to calculating and the current data display in the tunnel.

In $2-d$, it is difficult to show the real stratified tunnel coordinates within one drawing, and the connection among layers can not be shown. In 3-d, the system can provide rich layer management tools to hide unimportant data in the complex ventilation network and will focus on shown data.

\section{Conclusion}

(1)According to the actual situation and optimization and transformation objectives and requirements, we pertinently put forward three optimization schemes. Based on analysis of these simulations and optimizations, scheme three becomes the best solution.

(2) According to comparisons with two-dimension ventilation calculating software in the practical application, it is concluded that the Ventsim system takes advantages over $2 \mathrm{~d}$.

(3)Ventsim is applied to the simulations of Majiagou coal mine ventilation system by building ventilation system models and adjusting parameters, the mine ventilation system optimization scheme. Thus showing that applying Ventsim to ventilation design is practical. It is of some guiding significance for management researchers to find problems and optimize ventilation network.

\section{References}

[1]LUO Zhen-jiang, etc. The application of Ventsim in mine ventilation [J].Journal of nonferrous metallurgy design and research, 2009, 21 (3).

[2]DENG Hong-wei, etc. Ventilation optimization study of YunXi new mountain ore block based on Ventsim [J].Journal of mining technology, 2010, (4).

[3]WANG Ying-min, etc. Mine ventilation and safety [M]. Beijing: metallurgical industry press, 1978.

[4] LI Chun-min. The application of OpenGL in mine engineering $3 \mathrm{~d}$ visual simulation system $[\mathrm{J}]$. Journal of Beijing science and technology university, 2004 (5) : 457458.

[5] WEI Lian-jiang, WANG De-ming, WANG Qi, etc. the key research on building visualization of mine ventilation system [J]. Safety of coal mine, 2007, 6 (4) - 9.

[6] TIAN Hong-jian, WANG Shu-gang. Mine ventilation network multi-function simulation visualization [J]. Coal mine safety, 2008 (4) : -

[7] JIA Peng-tao, CHANG Xin-tan. Mine ventilation visual system based on the MapObjects [J]. Coal science and technology, 2002, (12) : 50- 52.

Supported by"the Fundamental Research Funds for the Central Universities" (3142013103)

(3142012029)

Introduction of author: ZHANG Jing-gang (1981.10-), male, born in Yantai of Shandong, Graduated from China mining university (Beijing) security technology and engineering doctor, a safety engineering lecturer of north China institute of science and technology, engaged in the coal mine safety, safety management and safety evaluation. E-mail: xagn@163.com Telephone:13463612776 